Proceedings of SALT 25: 163-183, 2015

\title{
A compositional account of the eventive/stative ambiguity of German causal von-modifiers*
}

\author{
Claudia Maienborn \\ University of Tübingen
}

\author{
Johanna Herdtfelder \\ University of Tübingen
}

\begin{abstract}
The paper develops a compositional semantics of German causal vonmodifiers that derives eventive and stative readings of causal von from a single lexical entry and allows for coercive adaptions to account for the observed range of interpretive adjustments. Characteristic features of the interpretation such as the inferential behavior of causal von-modifiers and the holistic effect of the stative reading are explained as following from independently motivated conceptual assumptions concerning the spatiotemporal grounding of causation.
\end{abstract}

Keywords: causation, modification, eventive/stative ambiguity, events, tropes, copula, adjectival semantics, coercion, holistic effect

\section{Introduction}

In contemporary linguistics, causation is generally conceived of as a relation that holds between events. This is typically represented by a primitive relation CAUSE $\left(\mathrm{e}_{1}, \mathrm{e}_{2}\right)$, which is meant to express that the occurrence of a causing event $\mathrm{e}_{1}$ causes a resulting event $e_{2}$ to occur; see, e.g., Copley \& Wolff 2014. Very rarely, exceptions to this standard case are mentioned that do not fit into the event-based picture of causation but rather suggest that - apart from events - certain stative entities may also enter into causal relations. For instance, Dowty (1979: 103) cites sentence (1), which he credits to Fillmore, as an instance of a stative causal relation; see also the discussion in Hobbs 2005: 207 and Solstad 2006: 97.

(1) Mary's living nearby causes John to prefer this neighborhood.

* The research reported here was supported by the Deutsche Forschungsgemeinschaft (project A1 of the SFB 833 “The Construction of Meaning"). We would like to thank our project members, Sebastian Bücking, Frauke Buscher, Julia Lukassek, Anna Prysłopska, and Sarah Zobel, as well as the SALT 25 audience for very helpful comments and feedback.

(C) Maienborn and Herdtfelder 
Yet, beyond some rather cursory remarks, the case of stative causation has not received particular attention within linguistic research. More recently, Moltmann $(2007,2009,2013,2014)$ has argued for the ontological category of tropes as concrete property manifestations in an individual. According to Moltmann, tropes, such as the redness of an apple or Mary's paleness, share with events the property of being causally efficacious. This is illustrated by sentence (2), which identifies Mary's paleness as the cause for the shock; see Moltmann 2013: 301.

\section{(2) Mary is shockingly pale.}

Moltmann's trope theory provides a starting point to explore in more detail the notion of stative causation. In the present paper, we will use German causal vonmodifiers ('from') as a means of gaining deeper insights into the linguistic expression of stative and eventive causation, what they have in common, and how they differ. Causal von-modifiers of adjectival copula sentences support an eventive as well as a stative causal reading. This is illustrated by the sentences in (3).

a. Paul war müde von der Reise.

eventive reading Paul was tired from the trip

b. Der Platz ist weiß von den Hagelkörnern. stative reading The square is white from the hailstones

In (3a), the von-phrase expresses an eventive causal relation between a trip and an event that results in Paul being tired. In (3b), in contrast, the causal relation does not hold among events but is of some stative nature. Informally speaking, the cause for the square being white is provided by some property related to the hailstones, viz. their whiteness. Furthermore, the hailstones are understood as being holistically located on the square. A sentence such as (4) is ambiguous.

(4) Das Dach ist weiß von den Tauben. ambiguous The roof is white from the pigeons

Besides its stative reading, according to which the roof's whiteness is due to the whiteness of the pigeons (that are located all over the roof), it also has an eventive reading, according to which the roof is white, for instance, because some pigeons (which need not be present anymore) soiled it. As this example indicates, the interpretation of causal von may involve certain coercive adaptions as, for instance, the inference of a suitable event from a given object referent.

In the present paper, we will argue that the ambiguity of causal von-modifiers observed in (3) and (4) can be accounted for parsimoniously if we develop an adequate notion of stative causation on a par with eventive causation. The structure of the article is as follows. In Section 2, we present four core observations concerning the interpretation of causal von-modifiers in adjectival copula sentences that are to be explained. Section 3 is devoted to the ontology of events and tropes as causal relata. Section 4 develops a compositional semantics for causal 
von that exploits syntactic differences for deriving eventive and stative readings from a single lexical entry and allows for coercive adaptions to account for the observed range of interpretive adjustments. The formal analysis is couched in terms of Asher's (2011) Type Composition Logic.

\section{Core observations on German causal von-modifiers}

\subsection{Preliminary remarks}

Let us start our discussion of causal von with a remark of caution. The interpretations of German von and English from - although they overlap significantly do not match exactly. In (5a) and (5b), for instance, von corresponds to from. However, whereas stative causal relations are expressed uniformly with von in German, English uses both from and with; see (5b-c). Furthermore, von is also used for the expression of agents as in (5d).

(5) a. Paul ist müde von der Reise. Paul is tired from the trip.

b. Das Gesicht war schwarz von dem Staub. The face was black from the dust.

c. Der Hut war schwarz von/*mit Käfern. The hat was black *from/with bugs.

d. Dieses Bild wurde von Paul gemalt. This picture was painted by Paul.

Note furthermore that von appears to impose stronger restrictions than from on the kind of causal relation it may express. The English sentences in (6) were judged as well-formed by native speakers of English, but their respective German translations with von are ruled out as ungrammatical. In order to refer to such constellations in German, one would have to resort to the more liberal causal preposition wegen ('because-of'); see (7).

(6) a. The light was pink from my rose-colored glasses.

b. The square was blue from the nearby skyscraper.

c. The living room was cold from the hole in the basement door.

d. Paul was poor from bad investments.

(7) a. * Das Licht war rosa von meiner rosé-getönten Brille. $\checkmark$ wegen

b. * Der Platz war blau von dem nahen Wolkenkratzer. $\checkmark$ wegen

c. * Das Wohnzimmer war kalt von dem Loch in der Kellertür. $\checkmark$ wegen

d. * Paul war arm von schlechten Geldanlagen. $\checkmark$ wegen

Thus, there is a subtle but significant difference between the causal relations expressed by German von and English from. This should be kept in mind throughout the paper. We will discuss the particular restrictions on causation imposed by von in Section 3.

A second remark concerns the case of von-arguments. Some adjectives and adjectivized participles take von-PPs as arguments; see (8). 
(8) a. Die Schüssel ist voll von / mit Kirschen.

The bowl is full of / with cherries

b. Unsere Früchte sind frei von Pestiziden.

Our fruits are free of pesticides

c. Paul ist beeindruckt / enttäuscht von Marias Vortrag.

Paul is impressed / disappointed by Maria's talk

Adjectives such as voll ('full') or frei ('free') are inherently relational and select for an internal argument. Similarly, adjectivized participles such as beeindruckt ('impressed') or enttäuscht ('disappointed') inherit a stimulus argument from their verbal base. Adjectival von-arguments fall outside the scope of the present paper. Here, we are only interested in von-PPs that do not fill a dedicated argument slot but act as modifiers.

In the following, we will present four core observations concerning the interpretation of causal von-modifiers that our semantic analysis strives to account for.

\subsection{Inference patterns}

Eventive and stative readings of causal von-modifiers differ with respect to two inferential patterns. First, only stative von supports the inference that von's internal NP-referent is located on the subject referent at the predication time; see (9).

a. Der Platz ist weiß von den Hagelkörnern. $\rightarrow$ The hailstones are The square is white from the hailstones on the square.

b. Die Bank ist dreckig von den Schuhen. $\rightarrow$ The shoes are on The bench is dirty from the shoes the bench.

For (9a) to be true, the hailstones must be located on the square at the predication time. This is not the case for (9b). The shoes may still be on the bench, but they don't need to be. Their location is irrelevant for the truth conditions of (9b). Secondly, only stative von implies that the main predicate also holds for von's internal NP-referent at the predication time. This can easily be observed in a case like (10a) with the newly invented fantasy noun Mimbeln ('mimbles'). There is no world knowledge available about mimbles. So we have no expectations about their color. Nevertheless, from (10a) we conclude that the mimbles must be white. No such inference is valid in the case of eventive causal von-modifiers; see (10b).

(10) a. Der Platz ist weiß von den Mimbeln. The square is white from the mimbles

$\rightarrow$ The mimbles are white.

b. Die Bank ist dreckig von den Schuhen. $\rightarrow$ The shoes are The bench is dirty from the shoes dirty.

That is, stative von supports - roughly speaking - some kind of "property transfer" from von's internal NP-referent to the subject referent. In (10a), the 
square's whiteness is inherited from the whiteness of the mimbles. There is a certain margin of freedom in inferring the relevant property though. In (11), for instance, the adjective bleich carries a selectional restriction for human beings. This restriction is not met by flour dust. The respective property, for which the inference pattern holds, is that of having a bright, almost white color in this case.

(11) Ihr Gesicht war bleich von Mehlstaub.

Her face was pale from flour-dust

The two inference patterns illustrated in (9) and (10) may serve as diagnostics for differentiating eventive and stative readings of causal von; see Herdtfelder \& Maienborn 2015 for a corpus study on causal von-modifiers in adjectival copula sentences which was based on these diagnostics.

\subsection{Holistic effect}

As already mentioned in the introduction, a prominent feature of von's stative reading is the holistic interpretation of its internal NP-referent. In the sentences in (12), the internal NP-referent is interpreted as being located all over (relevant parts of) the subject referent.

(12) a. Der Boden war schwarz von Ameisen.

The floor was black from ants

b. Die Luft ist schwer von Blütenduft.

The air is thick from blossom-scent

Rapoport (2014) has argued for the parallel case of with (e.g., The floor was black with ants.) that the observed holistic effect is due to the particular semantics of the preposition with (rather than being construction-specific). In the same spirit, we will argue in Section 3 that the holistic effect can be derived from the semantics of von. More specifically, we will propose that it follows from the conditions on spatiotemporal contiguity imposed on stative causation.

\subsection{Direct causation}

Causal von-PPs express non-agentive causal relations. The cause is neither in control of the event (i.e., an agent) nor under external control (i.e., an instrument); e.g., DeLancey 1984. More specifically, von's internal NP-referent is qualified as a non-volitional cause; see the notion of a "causer," e.g., in Rappaport Hovav \& Levin 2000, Alexiadou \& Schäfer 2006, Rothmayr 2009, and Schäfer 2012.

Moreover, causal von is restricted to expressing a narrow notion of "direct causation." The distinction between direct vs. indirect causation is a widely discussed opposition within the literature on causation; see, e.g., Shibatani 1976, Talmy 1976, Dowty 1979: 98f, Wolff 2003, Vecchiato 2011, and Copley \& Wolff 
2014. Direct causation is commonly understood as an immediate causal relationship between a cause and an effect without intervening entities, whereas indirect causation allows cause and effect to be related via longer causal chains. Take (13) as an illustration.

(13) a. Paul ist müde von der Reise.

Paul is tired from the trip

b. Paul ist müde wegen der Reise.

Paul is tired because-of the trip

In (13a) von requires that there is an immediate, non-interrupted relationship between the trip and Paul becoming tired: First of all, Paul must have taken part in the trip. Secondly, von implies a temporal ordering according to which the trip must precede Paul's tiredness, and, furthermore, no (significant) temporal gap is permitted between the trip and the onset of Paul's tiredness. For instance, (13a) could not refer to a situation in which Paul takes part in a trip and - in order to relax his stiff limbs - mows the lawn upon his return home and only afterwards becomes tired. Causal von differs sharply from the more liberal causal preposition wegen ('because-of') in this respect. The wegen-sentence $(13 \mathrm{~b})$ only requires that the trip somehow relates to the cause of Paul's tiredness. Paul is neither required to take part in the trip nor are there any temporal restrictions. For instance, (13b) might well refer to a situation where Paul is planning a future trip or is suffering from nightmares about a trip that took place long ago. Such scenarios are excluded for von. Similar conditions hold for the case of stative causal von. Sentence (14a) requires spatial and temporal contiguity between the ants being on the floor and the floor being black. The ants must be located on the floor at the time of the predication; see the inference pattern in (9). The wegen-sentence (14b), by contrast, also tolerates an indirect causal relationship, where no spatiotemporal contiguity between cause and effect holds. For instance, (14b) could refer to a situation where the floor is painted black because this keeps ants away.
a. Der Boden ist schwarz von den Ameisen. The floor is black from the ants
b. Der Boden ist schwarz wegen der Ameisen. The floor is black because-of the ants

Several definitions of direct causation have been suggested, mostly in connection with a discussion of lexical vs. periphrastic causatives; see, e.g., Shibatani 1976 and Vecchiato 2011. In the following, we will adopt Wolff's (2003) Nointervening-cause criterion:

(15) No-intervening-cause criterion:

Direct causation is present between the causer and the final causee in a causal chain (1) if there are no intermediate entities at the same level of 
granularity as either the initial causer or final causee, or (2) if any intermediate entities that are present can be construed as an enabling condition rather than an intervening causer.

Wolff 2003: 4f

We have already seen an illustration of Wolff's first condition on direct causation when discussing sentence (13a): von, as representative for direct causation, requires that Paul's trip immediately leads to his tiredness. No intervening event of the same level of granularity, such as, for instance, the mowing of his lawn, is tolerated. The preposition wegen, in contrast, would be fine in such a scenario of indirect causation. That is, causal chains that are referred to by wegen do not have to meet Wolff's No-intervening-cause criterion. ${ }^{1}$

Note that direct causation differs from indirect causation in not being transitive. Transitivity is generally considered a core property of causation; see, e.g., Lewis 1973: 563. However, it only holds for indirect causation. (16) illustrates that the causal relation expressed by von is in fact non-transitive and differs from wegen in this respect. If the bench is dirty from the shoes (16a), and the shoes are dirty from the hike (16b), it does not follow that the bench is dirty from the hike (16c), but we may only conclude that the bench is dirty because of the hike (16d).
a. Die Bank ist dreckig von den Schuhen.
(bench dirty from shoes)
b. Die Schuhe sind dreckig von der Wanderung. (shoes dirty from hike)
c. $\rightarrow$ Die Bank ist dreckig von der Wanderung. (bench dirty from hike)
d. $\rightarrow$ Die Bank ist dreckig wegen der Wanderung. (b. dirty because-of hike)

In sum, causal von-modifiers express a narrow notion of direct causation in the sense of Wolff (2003), which is non-transitive and imposes particular conditions on spatiotemporal contiguity between the cause and its effect. These conditions will be spelled-out in Section 3.

\subsection{Coercion}

Finally, it is worth noting that causal von tolerates certain coercive adaptions in case of type mismatches. To give just one example, eventive causal von requires an internal argument of type event. This causing event might be given either explicitly, as, for example, the trip in (13a), or, alternatively, in case of a type conflict, it might also be inferred from an object referent as in (17). The symbol ' $\sim$ ' is used for pragmatic inferences based on world knowledge.

1 The second condition in Wolff's definition of direct causation ensures that the use of an instrument by an agent does not count as intervening cause, whereas a second volitional agent would count as an intervening cause. Since we already established above that causal von is reserved for non-agentive causation, Wolff's second condition can be neglected for our purposes. 
a. Paul war satt von der Pizza. Paul was full from the pizza

b. Paul war müde von den Tabletten. $\sim$ from the release of their inPaul was tired from the pills $\sim$ from eating the pizza gredients (after taking them)

In (17a), the most natural cause for being full that is related to a pizza is an eating event. For (17b), an obvious reason related to the pills for Paul becoming tired is the release of the ingredients of the pills after taking them. Yet, in an appropriate context (17b) could also be interpreted as expressing that Paul became tired by some action that he performed with the pills, for instance, checking their expiry date. That is, the interpretation of sentences such as (17) is based on event coercion: a combinatory conflict is resolved by accommodating a contextually appropriate event based on the given object referent.

The semantic approach that we develop in the following aims at accounting for the above core observations concerning the interpretation of causal von.

\section{Ontology: Events and tropes as causal relata}

As mentioned in the introduction, current linguistic theories generally take causation to be a relation that holds between events, for example, Eckardt 2000, Hobbs 2005, and Vecchiato 2011 among many others. Moltmann (2007, 2009, 2013 , 2014) extends this view by arguing for an ontological category of tropes, which shares with events the property of having causal force. Tropes are concrete property manifestations in an individual. They act as implicit arguments of adjectives and can be referred to by adjective nominalizations such as German Schönheit 'beauty', and Zufriedenheit 'satisfaction' or English redness, happiness, and paleness. Trope arguments are targeted by modifiers such as the ones in (18). As Moltmann (2013: 300) points out, "these modifiers represent precisely the kinds of properties that tropes are supposed to have, such as properties of causal effect, of perception, and of particular manifestation." 2

(18) a. Mary is visibly / profoundly happy.

b. Mary is extremely / frighteningly pale.

For the present purposes (19) may serve as an illustration for a trope-based semantics of an adjective such as white. The variable $\mathrm{x}$ ranges over physical objects, i.e., $x$ is of type phys, and the variable $r$ is of type trope. 'BEARER' stands for the bearerhood relation relating a trope to its bearer; see Moltmann 2013: 302f.

$$
\text { wei } \beta \text { ('white'): } \lambda \mathrm{x} \text { :phys } \lambda \mathrm{r} \text { :trope [BEARER }(\mathrm{x}, \mathrm{r}) \& \text { WHITENESS (r)] }
$$

2 See Maienborn 2015 for an overview of the ontological properties of events and tropes as opposed to (certain) states. 
Adopting Moltmann's notion of tropes, we want to propose that causation holds either between events or between tropes. Thus, the causal relata are either of type event or of type trope as in (20). (20a) covers the case of eventive causation and $(20 \mathrm{~b})$ that of stative causation. ${ }^{3}$

(20) a. CAUSE $\left(\mathrm{e}_{1}, \mathrm{e}_{2}\right)$

with $\mathrm{e}_{1}, \mathrm{e}_{2}$ as variables over events

b. CAUSE $\left(\mathrm{r}_{1}, \mathrm{r}_{2}\right)$ with $\mathrm{r}_{1}, \mathrm{r}_{2}$ as variables over tropes

Note that abstract (Kimian) states don't have causal force and hence don't pattern with events and tropes in this respect. The minimal pair in (21) compares a trope referring adjectival nominalization with a nominalized infinitival copular expression, which refers to K-states (e.g., Bücking 2012, Moltmann 2014). As (21) shows, only the former are legitimate arguments of causal von-modifiers. That is, the concrete humidity of the air causes the beds to be wet; see (21a). The K-state of the air being humid, in contrast, has no causal force; see (21b).

(21) a. Die Betten waren nass von der Luftfeuchtigkeit. The beds were wet from the air-humidity

b. *Die Betten waren nass vom Feucht-Sein der Luft. Thebeds were wet from.the humid-be.inf of.the air

The two causal patterns in (20) provide the ontological basis for spelling out the notion of direct causation. The conditions on spatiotemporal contiguity that are imposed by direct causation are formulated in the following ontological axioms. (The functions $\tau$ and $\pi$ map eventualities and tropes onto their temporal and spatial dimensions respectively.)

(22) Spatiotemporal contiguity axioms for eventive causation: ${ }^{4}$

a. $\forall \mathrm{e}_{1} \forall \mathrm{e}_{2} \operatorname{CAUSE}\left(\mathrm{e}_{1}, \mathrm{e}_{2}\right) \rightarrow \tau\left(\mathrm{e}_{1}\right) \supset \tau\left(\mathrm{e}_{2}\right) \quad \supset$ : temporal abutment

b. $\forall \mathrm{e}_{1} \forall \mathrm{e}_{2} \operatorname{CAUSE}\left(\mathrm{e}_{1}, \mathrm{e}_{2}\right) \rightarrow \pi\left(\mathrm{e}_{1}\right) \circ \pi\left(\mathrm{e}_{2}\right) \quad \circ$ spatial contact

3 The causal patterns in (20) require that their arguments are of the same type. Either both arguments are of type event, or they are both of type trope. The two remaining logical possibilities (i) and (ii) are ruled out for conceptual reasons.

(i) CAUSE $(e, r)$

(ii) CAUSE (r, e)

As to (i), an event can only cause a change of state, i.e., the initiation of a trope but not a bare trope per se. As to (ii), to cause an event requires some dynamic input, a transition. Again, a bare trope cannot initiate an event. So, the two patterns in (20) are, in fact, the only available options of how direct causation can be realized; see also Schaffer's (2014) metaphysical harmony requirement for causal relata.

4 Our formulation of the conditions on spatiotemporal contiguity for the eventive case is similar in spirit to Vecchiato's (2011: 170) definition. Vecchiato does not take into account stative causation though. See, e.g., Kamp \& Reyle 1993 for the temporal relation of abutment. 
In the eventive case, the causing event $\mathrm{e}_{1}$ immediately precedes the resulting event $\mathrm{e}_{2}$; see (22a). And there is some kind of physical contact between the two events. This is formulated in (22b) in terms of spatial contact. For the case of eventive causal von, this amounts to demanding that the bearer of the resulting trope must be in spatial contact with $\mathrm{e}_{1}$, typically by taking part in $\mathrm{e}_{1}$.

The axioms in (23) account for the respective conditions in the stative case: The temporal extension of the resulting trope $r_{2}$ lies within the temporal extension of the causing trope $r_{1}$; see (23a). And $r_{2}$ 's spatial extension is included by the spatial extension of $r_{1}$; see $(23 b)$.

(23) Spatiotemporal contiguity axioms for stative causation:

a. $\forall \mathrm{r}_{1} \forall \mathrm{r}_{2} \operatorname{CAUSE}\left(\mathrm{r}_{1}, \mathrm{r}_{2}\right) \rightarrow \tau\left(\mathrm{r}_{1}\right) \supseteq \tau\left(\mathrm{r}_{2}\right)$

b. $\forall \mathrm{r}_{1} \forall \mathrm{r}_{2} \operatorname{CAUSE}\left(\mathrm{r}_{1}, \mathrm{r}_{2}\right) \rightarrow \pi\left(\mathrm{r}_{1}\right) \supseteq \pi\left(\mathrm{r}_{2}\right)$

The ontological axioms in (22) and (23) spell out the conditions on direct causation that we identified in Section 2.4. They are independently motivated due to the spatiotemporal nature of events and tropes and they provide a straightforward explanation of some of causal von's core properties observed in Section 2. In particular, they account for the inferential pattern in (9), and they provide an explanation for the characteristic holistic effect observed for the stative reading of causal von.

According to the inference pattern in (9), stative von implies that von's internal NP referent is located on the subject referent at the time of the predication. This inference follows from the axiom (23b). Since tropes are dependent on their bearers, spatial inclusion among tropes implies spatial contact between their bearers. That is, in order for the spatial extension of the resulting trope $r_{2}$ to fall within the spatial extension of the causing trope $r_{1}$, the bearer of $r_{1}$ must be located on the bearer of $\mathrm{r}_{2}$.

Next, what about the holistic effect of stative causal von? Why is it that in (3b), for instance, the hailstones are understood as being located all over (relevant parts of) the square? This can be explained with reference to a general "totality condition" on predication: The arguments of a predicate are indivisible with respect to the predication; see Löbner $2000 .^{5}$ In the case of (3b), for example, the predication of being white holds for (the surface of) the whole square. That is, the spatial extension of the square's whiteness covers the whole square. Therefore given (23b) - the spatial extension of the hailstones' whiteness must include this region. From this it follows that the square is covered by the hailstones. This explains the characteristic holistic effect observed with the stative reading of causal von. The holistic interpretation is accounted for on the basis of independently mo-

5 Löbner (2000: 239) formulates this totality condition in terms of a Presupposition of Indivisibility: "Whenever a predicate is applied to one of its arguments, it is true or false of the argument as a whole." 
tivated assumptions concerning spatiotemporal contiguity restrictions on trope causation and on the nature of predication. Our explanation shares with Rapoport (2014) the assumption that the source of the holistic interpretation is to be found in the semantics of the preposition; see Section 2.3. With (23) we propose an ontologically grounded implementation of this assumption.

So far, we have developed a semantic analysis of causal von in terms of direct causation that reduces the differences between its eventive and its stative readings to a sortal contrast. The causal relation holds either between events or between tropes with their respective spatiotemporal contiguity conditions. Interpretive characteristics, such as the holistic effect observed with the stative reading of causal von, follow from these assumptions straightforwardly. In the following, we will show that the selection for the sortal type, event or trope, and hence for von's reading, is triggered by the syntactic position of the modifier.

\section{A compositional semantics for causal von-modifiers}

\subsection{Two syntactic adjunction sites}

In this section we will sketch our core assumptions concerning the syntax of causal von-modifiers, which provide the starting point for our compositional approach. Due to lack of space these assumptions will only be motivated with some findings from our corpus study, but see Maienborn \& Herdtfelder 2015 for a more thorough discussion of the syntax of causal von-modifiers.

The corpus study reported in Herdtfelder \& Maienborn 2015 comprises 358 adjectival copula sentences with causal von-modifiers. Based on the two inference patterns in (9) and (10), 249 of them were classified as eventive and 109 as stative. Furthermore, the sentences were analyzed with respect to (i) the (non-)adjacency of the adjective and the von-PP, and (ii) the syntactic order of the adjective and the von-PP in the case of adjacency. The relevant findings are the following:

(24) Eventive reading:

(i) $88 \%$ adjacent, $12 \%$ non-adjacent

(ii) $75 \%$ Adj $>$ PP, $25 \%$ PP $>$ Adj

(25) Stative reading:

(i) $97 \%$ adjacent, 3\% non-adjacent

(ii) $94 \% \mathrm{Adj}>\mathrm{PP}, 6 \% \mathrm{PP}>\mathrm{Adj}$

The data in (24) and (25) show that the order Adj > PP is the unmarked order for both readings. Deviations from this order are particularly marked in information structural terms; see Herdtfelder \& Maienborn 2015 for details. These data support the view that Adj > PP is the base order. Given that German is verb final, this implies that the causal von-modifier must be part of the AP. Otherwise the 
copula could not combine first with its AP-complement. Thus, from these observations we may conclude that the von-PP is a modifier that adjoins to some projection of the adjective.

The corpus data show furthermore that - beyond this basic conformity - the two readings differ with respect to both the extent of the PP's adjacency to the adjective and its syntactic mobility. A $\chi^{2}$ test (e.g., Siegel 1956) revealed that nonadjacency is significantly less frequent for the stative vs. the eventive reading $(3 \%$ vs. $\left.12 \% ; \chi^{2}(1)=7.83, p<.05\right)$. And a second, independent $\chi^{2}$ test revealed that in the adjacent cases the order PP $>$ Adj is significantly less frequent for the stative vs. the eventive reading $\left(6 \%\right.$ vs. $\left.25 \% ; \chi^{2}(1)=17.73, p<.01\right)$. Thus, the two readings are accompanied by characteristic distributional differences. Specifically, the corpus data support the view that stative von is positioned closer to the adjective than eventive von and does not admit intervening linguistic material. This hints at the possibility of different AP-internal base adjunction sites. For the time being, we will account for these observed differences by assuming that eventive von adjoins at the AP-periphery (AP-adjunct), whereas stative von has a base position in the immediate vicinity of the adjective (A-adjunct). See Maienborn \& Herdtfelder 2015 for a more thorough discussion, where this assumption is further supported by a series of additional syntactic and semantic diagnostics.

\subsection{Compositional semantics with type accommodation}

The previous section has established a correlation between the semantic interpretation of a causal von-modifier (eventive or stative) and its syntactic position (AP-adjunct or A-adjunct). This may serve as the starting point for developing a compositional solution. Our analysis of the compositional semantics of causal von-modifiers will be spelled out in Asher's (2011) Type Composition Logic (TCL), which provides us with a context-sensitive model of type driven lexical semantics. Basically, TCL assumes two levels of semantic representation: a level of Logical Form with the usual model-theoretic interpretation, and a level of types with a proof-theoretic interpretation. Types, which Asher conceives of as mental concepts, may convey arbitrarily fine-grained information organized in terms of a type hierarchy.

Let us begin by providing the semantic ingredients for the stative reading of von in (3b). ${ }^{6}$ The lexical entry for an adjective such as white was already introduced in (19) and is repeated in (26). Furthermore, we assume an operation of Existential Trope Closure (ETC) at the AP-boundary as in (27). ETC binds the adjective's trope argument existentially and introduces an argument for a Kimian

6 For ease and brevity of presentation we will use a simplified TCL notation. A variable's type is added in bold face after a column. Furthermore, to save space and to improve readability, type information will be omitted if a variable's type is either clear or irrelevant in a given context. 
state (see Section 3) at which the bearerhood relation holds. (28) provides the lexical entry for the copula sein ('to be'), and in (29) the minimal part of an I'semantics is given that is of interest here. Its core contribution consists in the existential binding of the VP's eventive or stative argument. The semantic representation of definite NPs will be abbreviated as in (30).

(26) weiß ('white'): $\lambda \mathrm{x}$ :phys $\lambda \mathrm{r}$ :tr [BEARER $(\mathrm{x}, \mathrm{r}) \&$ WHITENESS (r)]

(27) Existential trope closure (ETC): $\lambda \mathrm{P} \lambda \mathrm{x} \lambda \mathrm{s}: \mathrm{st} \exists \mathrm{r}: \operatorname{tr}[\mathrm{s}: \mathrm{P}(\mathrm{x})(\mathrm{r})]$

(28) $\operatorname{sein}($ 'to be'): $\lambda \mathrm{P} \lambda \mathrm{x} \lambda \mathrm{s}: \mathrm{st}[\mathrm{P}(\mathrm{x})(\mathrm{s})]$

(29) $I^{0}: \quad \lambda P \lambda x \exists s: e v \sqcup s t[P(x)(s)]$

(30) der Platz ('the square'): DEF x:phys [SQUARE (x)] or: def-sqphys

The relevant steps of a compositional derivation for a simple copula sentence are given in (31). Thus, the sentence expresses that there is a K-state s at which the square is the bearer of a concrete manifestation of whiteness $r$.

(31) a. [AP Weiß]: $\lambda \mathrm{P} \lambda \mathrm{x} \lambda \mathrm{s} \operatorname{\exists r}[\mathrm{s}: \mathrm{P}(\mathrm{x})(\mathrm{r})](\lambda \mathrm{x} \lambda \mathrm{r}$ [BEARER $(\mathrm{x}, \mathrm{r}) \&$ WHITENESS (r)])

b. $\quad\left[\mathrm{VP}\left[{ }_{\mathrm{AP}}\right.\right.$ Weiß] sei- $]$ :

$=\lambda \mathrm{x} \lambda \mathrm{s}: \mathrm{st} \exists \mathrm{r}: \operatorname{tr}[\mathrm{s}: \operatorname{BEARER}(\mathrm{x}, \mathrm{r}) \&$ WHITENESS $(\mathrm{r})]$

$\lambda \mathrm{P} \lambda \mathrm{x} \lambda \mathrm{s}: \mathrm{st}[\mathrm{P}(\mathrm{x})(\mathrm{s})](\lambda \mathrm{x} \lambda \mathrm{s} \exists \mathrm{r}[\mathrm{s}: \operatorname{BEARER}(\mathrm{x}, \mathrm{r}) \&$ WHITENESS $(\mathrm{r})])$

$=\lambda \mathrm{x} \lambda \mathrm{s}: \mathrm{st} \exists \mathrm{r}: \operatorname{tr}[\mathrm{s}: \operatorname{BEARER}(\mathrm{x}, \mathrm{r}) \&$ WHITENESS $(\mathrm{r})]$

c. $\quad[\mathrm{I},[\mathrm{VP}[\mathrm{AP}$ Weiß $]$ war $]]$ :

$\lambda \mathrm{P} \lambda \mathrm{x} \exists \mathrm{s}[\mathrm{P}(\mathrm{x})(\mathrm{s})](\lambda \mathrm{x} \lambda \mathrm{s} \exists \mathrm{r}[\mathrm{s}: \operatorname{BEARER}(\mathrm{x}, \mathrm{r}) \&$ Whiteness $(\mathrm{r})])$

$=\lambda \mathrm{x}$ ヨs:st $\exists \mathrm{r}: \operatorname{tr}[\mathrm{s}: \operatorname{BEARER}(\mathrm{x}, \mathrm{r}) \&$ WHITENESS $(\mathrm{r})]$

d. [IP der Platz [VP [AP Weiß] war]]:

$\lambda \mathrm{x} \exists \mathrm{s} \exists \mathrm{r}$ [s: BEARER $(\mathrm{x}, \mathrm{r}) \&$ WHITENESS (r)] (def-sq $\left.q_{\text {phys }}\right)$

$=\exists$ s:st $\exists r: t r[s:$ BEARER $(d e f-s q$ phys,,$r) \&$ WHITENESS (r)]

Now, what about stative von? A straightforward implementation of our observations concerning the interpretation of stative von in the previous sections leads to (32) as the lexical entry.

(32) von ('from'):

$\lambda c: t r-\operatorname{tr}\left(\mathrm{HD}(\mathrm{c}) \subseteq\right.$ phys) $\lambda \mathrm{c}^{\prime}: \operatorname{tr}\left[\right.$ CAUSE $\left.\left(\mathrm{c}, \mathrm{c}^{\prime}\right)\right]$

stative reading

According to (32), von expresses a causal relation between two arguments c and c' which are both required to be of type tr(ope). Additionally, measures are taken in order to accommodate the type of von's internal argument $\mathrm{c}$ in case of a type conflict. This is modeled with Asher's so-called "polymorphic" types - a special kind of complex types whose value is specified in dependence on other arguments; see Asher 2011: Section 8.2. Polymorphic types play a crucial role in Ash- 
er's handling of coercion. If there is a type clash in the course of composition, i.e., the type of a compositionally provided argument does not meet the type requirements of the predicate, type accommodation via polymorphic types may take place. More specifically, our simplified notation of a polymorphic type ' $\alpha-\alpha(\beta)$ ' is to be understood as expressing that if a type requirement $\alpha$ cannot be met compositionally, $\alpha$ may be justified via $\beta$. That is, in case of a type clash, type accommodation may license the introduction of a new variable of type $\alpha$, whose type value is further specified dependent on the compositionally supplied type $\beta$. Notably, Asher (2011: Sections 3.5, 8.1) argues that coercion is crucially a matter of lexical semantics, not of general pragmatics. That is, whether or not a potential type clash may be resolved is something that must be determined in advance in the lexicon. In our case, the lexical entry for stative von in (32) establishes that von's internal argument $\mathrm{c}$ is regularly expected to be of type trope. Yet, if this type requirement is not met but the internal argument $\mathrm{c}$ is a physical object (i.e., a subtype of phys), then a trope argument may be accommodated based on c's type. (The head type function HD(c) maps c onto its most specific type.)

The compositional derivation for von's stative reading in sentence (3b) is provided in (33). The combination of von with the NP den Hagelkörnern leads to a type clash in (33a) (trope vs. phys). Due to von's polymorphic type, type accommodation may take place as in (33b). Note that type accommodation - which is a matter of the "internal semantics" - is accompanied by a transfer rule that mirrors the adaption at the level of LF. In our case, an existentially bound variable $\mathrm{c}$ of type $\operatorname{tr}(\mathbf{h}$-stone) - i.e., a hailstone-dependent trope - is introduced into LF which is related to the hailstones through the underspecified predicate $\phi_{\operatorname{tr}(\mathbf{h} \text {-stone) }}$. We assume a run-of-the-mill semantics for intersective modification, which leads to (33c) when combining the adjective with the von-PP; see, e.g., Heim \& Kratzer's (1998) composition rule of predicate modification. At the AP-boundary, ETC applies; see (33d). This and the following steps are the same as in the case of the simple copula sentence (31). The resulting semantic representation for von's stative reading in $(3 \mathrm{~b})$ is given in $(33 \mathrm{e})$.

(33) Der Platz war weiß von den Hagelkörnern.
a. $\quad[$ pp von den Hagelkörnern]: $\lambda c: t r-\operatorname{tr}\left(\mathrm{HD}(\mathrm{c}) \subseteq\right.$ phys) $\lambda \mathrm{c}^{\prime}: \operatorname{tr}\left[\right.$ CAUSE $\left.\left(\mathrm{c}, \mathrm{c}^{\prime}\right)\right]$ (def-h-st $\left.\mathrm{phys}\right)$

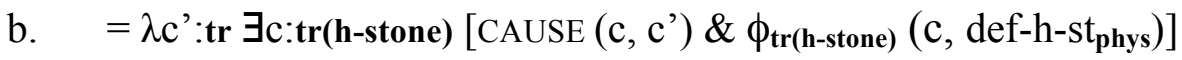
c. $\quad\left[{ }_{\mathrm{A}}[\mathrm{A}\right.$ Weiß] $[\mathrm{pp}$ von den Hagelkörnern]]:
$\lambda \mathrm{x}$ :phys $\lambda \mathrm{r}$ :tr $\exists \mathrm{c}$ :tr(h-stone) [BEARER(x, r) \& WHITENESS(r)
$\& \operatorname{CAUSE}(\mathrm{c}, \mathrm{r}) \& \phi_{\text {tr(h-stone) }}\left(\mathrm{c}, \mathrm{def}_{\text {-h-st }}\right.$ phys $\left.)\right]$
d. $\quad\left[{ }_{A P}[\mathrm{~A}[\mathrm{~A}\right.$ weiß] [PP von den Hagelkörnern] $]]$ :
$\lambda \mathrm{x} \lambda \mathrm{s}: \mathrm{st} \exists \mathrm{r}: \operatorname{tr} \exists \mathrm{c}: \operatorname{tr}(\mathrm{h}$-stone) [s: BEARER $(\mathrm{x}, \mathrm{r}) \&$ WHITENESS (r) 
Eventive/stative ambiguity of causal von-modifiers

$$
\begin{aligned}
& \left.\& \operatorname{CAUSE}(\mathrm{c}, \mathrm{r}) \& \phi_{\text {tr(h-st) }}(\mathrm{c}, \text { def-h-st } \text { phys })\right]
\end{aligned}
$$

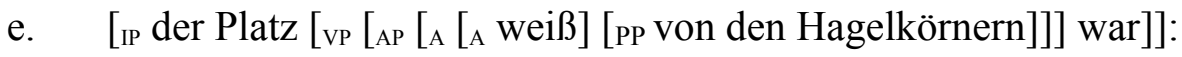

$$
\begin{aligned}
& \exists \text { s:st } \exists \text { r:tr } \exists \text { c:tr(h-stone) [s: BEARER (def-h-st } t_{\text {phys }}, \mathrm{r} \text { ) \& WHITENESS(r) } \\
& \left.\& \operatorname{CAUSE}(\mathrm{c}, \mathrm{r}) \& \phi_{\text {tr(h-stone) }}\left(\mathrm{c}, \text { def-h-st } \text { phys }_{\text {s }}\right)\right]
\end{aligned}
$$

In prose: There is a state $\mathrm{s}$ of a definite square being the bearer of a whiteness $r$ which is caused by a trope $c$ that is related in a semantically underspecified way to some definite hailstones. This is how far the compositional semantics gets us. Before turning to the pragmatic specification for c, let us first spell out von's eventive reading. The eventive variant of von's lexical entry is provided in (34).

$$
\begin{aligned}
& \text { von ('from'): eventive reading }
\end{aligned}
$$

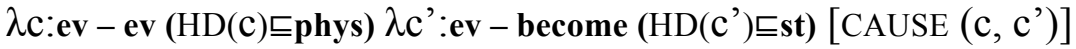

Eventive causal von patterns with stative causal von in tolerating internal arguments that denote physical objects. That is, if von's internal argument $\mathrm{c}$ is not of the requested type ev(ent) but rather phys, type accommodation may take place. Additionally, eventive causal von also tolerates type accommodation for its external argument. This is regularly expected to be of type event. However, apart from combining with eventive expressions (e.g., Cleopatra died from a snake bite.) or with the eventive copula werden/to become (e.g., Anna became tired from running.), eventive causal von-modifiers also tolerate external arguments of type state and coerce them into the result state of a hidden become operator. That is, if the modifier's target argument c' is not of the expected type event but of type state, this type clash can be resolved by inserting an event variable - more specifically, a becoming event that is dependent on the given state. (35) illustrates the derivation of the compositional semantics for (3a). Observe that von's internal NP der Reise ('the trip') is of type event. Thus, no type accommodation is required to compute the semantic representation of the PP; see (35a). Note furthermore that there is no way to combine the von-modifier directly with the adjective. Within the lexical entry of eventive von no provisions are made to accommodate a trope argument in the c'-position. This implies that an eventive von-modifier can only combine with an adjectival predicate after the ETC operation has taken place; see (35b). This accounts for our syntactic observations from Section 4.1: Eventive von adjoins at the AP-periphery. The combination exploits the lexically licensed type accommodation that introduces an event argument c' that is dependent on the adjectival state; see (35c). The subsequent composition proceeds as usual leading to (35d) as final semantic representation.

(35) Paul war müde von der Reise. ('Paul was tired from the trip.')

a. [pp von der Reise]:

$$
\lambda c^{\prime}: \mathbf{e v} \text { - become }\left(\mathrm{HD}\left(\mathrm{c}^{\prime}\right) \text { ㄷs) [CAUSE }\left(\text { def-trip }_{\mathbf{e v}}, \mathrm{c}^{\prime}\right)\right]
$$


b. [AP müde]: $\lambda \mathrm{x} \lambda \mathrm{s}: \mathrm{st} \exists \mathrm{r}: \operatorname{tr}[\mathrm{s}: \operatorname{BEARER}(\mathrm{x}, \mathrm{r}) \&$ TIREDNESS $(\mathrm{r})]$

c. $\quad\left[{ }_{A P}\left[{ }_{A P}\right.\right.$ müde $][\mathrm{PP}$ von der Reise $]$ :

$\lambda \mathrm{x} \lambda \mathrm{s}$ :st $\exists \mathrm{c}^{\prime}$ :become(st) $\exists \mathrm{r}: \operatorname{tr}[\mathrm{s}: \operatorname{BEARER}(\mathrm{x}, \mathrm{r}) \&$ TIREDNESS (r)

$\&$ CAUSE (def-trip ev,$\left.\left.c^{\prime}\right) \& \phi_{\text {become(st) }}\left(c^{\prime}, \mathrm{s}\right)\right]$

d. [IP Paul [VP [AP [AP müde] [PP von der Reise $]$ war]]:

$\exists$ s:st $\exists c^{\prime}:$ become(st) $\exists r: t r[s:$ BEARER (Paul, r) \& TIREDNESS (r)

\& CAUSE (def-trip ev,$\left.\left.c^{\prime}\right) \& \phi_{\text {become(st) }}\left(c^{\prime}, \mathrm{s}\right)\right]$

In prose: There is a state $\mathrm{s}$ of Paul being the bearer of a tiredness $r$ whose start c' was caused by a definite trip. Note that - although an eventive argument c' was inserted to resolve the type clash in (35c) - the AP's state argument $s$ is the one that remains compositionally active afterwards. That is, the given type accommodation is a local operation that does not affect the interpretation and later compositional behavior of the expression; it only affects the local predication (see Asher 2011: 223). In other words, a sentence such as (35) - although it requires the accommodation of an event - is still stative.

The interpretation of a sentence such as (17a) requires type accommodation for both von's internal and its external argument. The resulting semantic representation is provided in (36): There is a state of Paul being the bearer of a fullness that was initiated by an underspecified event related to a definite pizza.

(36) Paul war satt von der Pizza. ('Paul was full from the pizza.')

$\exists$ s:st $\exists c^{\prime}$ :become(st) $\exists r:$ tr $\exists e: e v($ pizza) [s: BEARER (Paul, r) \& FULLNESS (r)

$\& \operatorname{CAUSE}\left(\mathrm{e}, \mathrm{c}^{\prime}\right) \& \phi_{\text {ev(pizza) }}\left(\mathrm{e}, \operatorname{def}_{\text {-pizza }}\right.$ phys $\left.) \& \phi_{\text {become(st) }}\left(\mathrm{c}^{\prime}, \mathrm{s}\right)\right]$

The stative and eventive variants of causal von in (32) and (34) can be merged into a single lexical entry:

(37) Lexical entry for causal von: (eventive and stative reading)

$\lambda c: e v \sqcup \operatorname{tr}-\operatorname{ev} \sqcup \operatorname{tr}(H D(c) \sqsubseteq p h y s) \lambda c^{\prime}: e v \sqcup \operatorname{tr}-\operatorname{become}\left(H D\left(c^{\prime}\right) \sqsubseteq s t\right)$ [CAUSE $\left.\left(c, c^{\prime}\right)\right]$

The lexical entry in (37) summarizes the lexical part of our analysis. It determines that von's causal relata belong to the summation of the domains of events and tropes, and it licenses type accommodation if the causer argument $\mathrm{c}$ is instead a physical object. As for c', type accommodation is only available in the eventive case, provided that the compositionally supplied target is of type state. (37) ensures that the stative reading of causal von can only be generated if the modifier adjoins before the ETC operation takes place, i.e., the stative reading is based on A-adjunction, whereas the eventive reading can only be derived after ETC, if the modifier is adjoined at the AP-level. Thus, (37) accounts for the observed syntactic distribution of the two von-versions based on a single lexical entry with maximally identical semantic content. 
Eventive/stative ambiguity of causal von-modifiers

\subsection{Pragmatic type specification}

The last piece of our analysis concerns the pragmatic specification of the Logical Form. Those underspecified predicates that were introduced to solve a type conflict require a type specification process that is modeled in TCL in terms of a modal logic with a weak conditional operator '>'; see Asher 2011: 227ff. In (38), two such type specification rules are provided for illustration. Their application yields plausible interpretations for (36) and (33).

(38) Defeasible type specification rules

$$
\text { ('>': weak conditional) }
$$

a. $\quad \alpha \sqsubseteq$ food $\& \beta$ 巨animate \& CAUSE $(\operatorname{event}(\beta, \alpha)$, become $(\operatorname{state}($ fullness $(\beta))))$

$$
>\text { event }(\beta, \alpha)=\text { eat }(\beta, \alpha)
$$

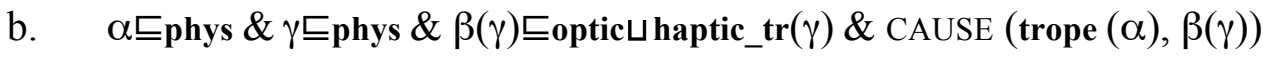

$$
>\text { trope }(\alpha)=\beta(\alpha)
$$

The rule in (38a) says that if $\alpha$ is a subtype of food, and $\beta$ is a subtype of an animate being, and some event involving individuals of type $\beta$ and $\alpha$ initiates a state of the individual of type $\beta$ exhibiting fullness, then this event most probably is an eating event. Rule (38a) provides us with a plausible pragmatic specification for (36). While the compositional semantics remains underspecified with respect to the kind of event that caused the fullness, drawing the inference in (38a) leads to (39) as a pragmatically specified sentence interpretation for (36). ${ }^{7}$

(39) Paul war satt von der Pizza.

\section{$\exists \mathrm{s} \exists \mathrm{c}^{\prime} \exists \mathrm{r}$ ヨe [s: BEARER (Paul, r) \& FULLnESs (r) \& CAUSE (e, c')}

\& EAT (e, Paul, def-pizza) \& BeCOME (c', s)]

Rules such as (38a) reflect our world knowledge and they may take into account further factors such as context and plausibility; see our remarks on several pragmatic specification options for (17b) in Section 2.5.

Finally, to account for the stative case we propose the inference rule in (38b): If some trope of a physical object of type $\alpha$ causes an optic or haptic trope $\beta$ in a physical object of type $\gamma$, then that trope corresponds to $\beta$. For (33) this yields (40) as a pragmatic specification.

(40) Der Platz war weiß von den Hagelkörnern.

$\exists \mathrm{s} \exists \mathrm{c}^{\prime} \exists \mathrm{c}$ [s: BEARER (def-square, c') \& WHITENESS (c') \& CAUSE (c, c') \& BEARER (def-h-stones, c) \& WHITENESS (c)]

According to (40), the square's whiteness is due to the whiteness of the hailstones. The rule $(38 \mathrm{~b})$ accounts for the observation that the stative reading of

7 A full formal specification will have to take into account additional arguments such as the agent of eating. For the moment, we set aside these technical details. 
causal von-modifiers is only licensed in combination with adjectives that denote optic or haptic properties; see Herdtfelder \& Maienborn 2015. Our analysis allows for the derivation of underspecified semantic representations with any kind of tropes, but then type justification fails, because there are no further type specification rules apart from (38b). That is, no well-formed type specification can be derived. The rule in (38b) is the source of the inference pattern (10), which we used as a diagnostic for von's stative reading in Section 2. And it provides an explanation for the intuitive impression mentioned in the beginning that there is some kind of "property transfer" from the cause to the effect.

To sum up, the present paper has developed a semantic analysis of causal vonmodifiers that accounts for the core empirical observations concerning the combinatorics and interpretation of causal von that we presented in Section 2. The eventive/stative ambiguity that we diagnosed for causal von could be traced back to a sortal contrast of the causal relata, which can be either events or tropes. Furthermore, this sortal contrast was argued to be reflected by the syntax. We proposed that eventive and stative von-modifiers occupy distinct syntactic base positions: Stative von is adjoined to A, and eventive von adjoins to AP. Based on this syntactic difference, we presented a compositional account that derives the two readings from a single lexical entry for von with maximally simple lexical content: CAUSE (c, c'). Our compositional account includes measures to solve type conflicts - always provided that these are lexically sanctioned. That is, our analysis advocates an approach towards coercion that takes the potential to reinterpret and adapt expressions according to combinatoric demands to be basically a matter of lexical semantics rather than being guided by general pragmatic strategies alone. We see this approach as providing a promising perspective for developing a sufficiently restrictive model of lexical semantics that is able to properly account for the observed flexibility and adaptivity of lexical meaning while adhering to compositionality as the core combinatoric principle. Further characteristic features of the interpretation of causal von modifiers such as their inferential behavior or the holistic effect on the interpretation of the internal argument of stative von could be explained as following from independently motivated conceptual assumptions concerning the spatiotemporal grounding of causation. Our analysis makes a strong case for assuming a stative notion of causation on a par with eventive causation. We argued that the two variants differ only in terms of the type of their arguments: events or tropes. All further differences could be derived from very general assumptions concerning the ontological nature of events and tropes as spatiotemporal particulars. 
Eventive/stative ambiguity of causal von-modifiers

\section{References}

Alexiadou, Artemis \& Florian Schäfer. 2006. Instrument subjects are agents or causers. In Donald Baumer, David Montero \& Michael Scanlon (eds.), West Coast Conference on Formal Linguistics (WCCFL) 25, 40-48. Somerville, MA: Cascadilla Proceedings Project.

Asher, Nicholas. 2011. Lexical Meaning in Context: A Web of Words. Cambridge: Cambridge University Press.

Bücking, Sebastian. 2012. Müdigkeit und Müde-Sein: Zur Semantik adjektivbasierter Zustandsnominalisierungen. Linguistische Berichte 232. 361-397.

Copley, Bridget \& Philip Wolff. 2014. Theories of causation should inform linguistic theory and vice versa. In Bridget Copley \& Fabienne Martin (eds.), Causation in Grammatical Structures, 11-57. Oxford: Oxford University Press.

DeLancey, Scott. 1984. Notes on agentivity and causation. Studies in Language 8(2). 181-213. doi:10.1075/s1.8.2.05del

Dowty, David. 1979. Word Meaning and Montague Grammar. Dordrecht: Reidel.

Eckardt, Regine. 2000. Causation, contexts, and event individuation. In James Higginbotham, Fabio Pianesi \& Achille C. Varzi (eds.), Speaking of Events, 105-121. New York, Oxford: Oxford University Press.

Heim, Irene \& Angelika Kratzer. 1998. Semantics in Generative Grammar. Oxford: Blackwell.

Herdtfelder, Johanna \& Claudia Maienborn. 2015. Causal modification of adjectival predicates: Insights from a corpus study on German causal von ('from'). In Nurit Melnik (ed.), Israel Association for Theoretical Linguistics (IATL) 30. MIT Working Papers in Linguistics.

Hobbs, Jerry. 2005. Toward a useful concept of causality for lexical semantics. Journal of Semantics 22(2). 181-209. doi:10.1093/jos/ffh024

Kamp, Hans \& Uwe Reyle. 1993. From Discourse to Logic: Introduction to Modeltheoretic Semantics of Natural Language, Formal Logic and Discourse Representation Theory. Dordrecht: Kluwer.

Lewis, David. 1973. Causation. Journal of Philosophy 70. 556-567.

Löbner, Sebastian. 2000. Polarity in natural language: Predication, quantification and negation in particular and characterizing sentences. Linguistics and Philosophy 23(3). 213-308. doi:10.1023/A:1005571202592

Maienborn, Claudia. 2005. On the limits of the Davidsonian approach: The case of copula sentences. Theoretical Linguistics 31. 275-316. doi:10.1515/thli. 2005.31.3.275

Maienborn, Claudia. 2007. On Davidsonian and Kimian states. In Ileana Comorovski \& Klaus von Heusinger (eds.): Existence. Semantics and Syntax, 107130. Berlin: Springer. 
Maienborn, Claudia. 2015. Events and states. To appear in R. Truswell (ed.), $O x-$ ford Handbook of Event Structure. Oxford: Oxford University Press.

Maienborn, Claudia \& Johanna Herdtfelder. 2015. Eventive and stative causation: On the grammar and interpretation of causal von-modifiers. Unpublished Ms. Tübingen.

Moltmann, Friederike. 2007. Events, tropes and truthmaking. Philosophical Studies 134(3). 363-403. doi:10.1007/s11098-005-0898-4

Moltmann, Friederike. 2009. Degree structure as trope structure: A trope-based analysis of positive and comparative adjectives. Linguistics and Philosophy 32. 51-94. doi:10.1007/s10988-009-9054-5

Moltmann, Friederike. 2013. On the distinction between abstract states, concrete states, and tropes. In Alda Mari, Claire Beyssade \& Fabio Del Prete (eds.), Genericity, 292-311. Oxford: Oxford University Press.

Moltmann, Friederike. 2014. States versus tropes. Comments on Curt Anderson and Marcin Morzycki: 'Degrees as kinds'. Natural Language and Linguistic Theory (Online first). doi:10.1007/s11049-015-9292-x

Rapoport, Tova. 2014. Central coincidence: The preposition with. Faits de langues 44(2). 159-173.

Rappaport Hovav, Malka \& Beth Levin. 2000. Classifying single argument verbs. In Martin Everaert, Peter Coopmans \& Jane Grimshaw (eds.), Lexical Specification and Insertion, 269-304. Amsterdam: John Benjamins.

Rothmayr, Antonia. 2009. The Structure of Stative Verbs. Amsterdam, Philadelphia: John Benjamins.

Schaffer, Jonathan. 2014. The metaphysics of causation. In Edward N. Zalta (ed.) The Stanford Encyclopedia of Philosophy (Summer 2014 Edition). http://plato. stanford.edu/entries/causation-metaphysics/

Schäfer, Florian. 2012. Two types of external argument licensing. The case of causers. Studia Linguistica 66(2). 1-53. doi:10.1111/j.1467-9582.2012. 011 92.x

Siegel, Sidney. 1956. Nonparametric Statistics for the Behavioral Sciences. New York: McGraw Hill.

Shibatani, Masayoshi. 1976. The grammar of causative constructions: A conspectus. In Masayoshi Shibatani (ed.), Syntax and Semantics. Vol. 6: The Grammar of Causative Constructions, 5-41. New York: Academic Press.

Solstad, Torgrim. 2006. Mehrdeutigkeit und Kontexteinfluss: Die Spezifikation kausaler Relationen am Beispiel von durch. PhD thesis. University of Oslo.

Talmy, Leonard. 1976. Semantic causative types. In Masayoshi Shibatani (ed.), Syntax and Semantics. Vol. 6: The Grammar of Causative Constructions, 43116. New York: Academic Press.

Vecchiato, Antonella. 2011. Events in the grammar of direct and indirect causation. PhD thesis. University of Southern California. 
Eventive/stative ambiguity of causal von-modifiers

Wolff, Philip. 2003. Direct causation in the linguistic coding and individuation of causal events. Cognition 88(1). 1-48. doi:10.1016/S0010-0277(03)00004-0

Claudia Maienborn

German Department

University of Tübingen

Wilhelmstr. 50

72074 Tübingen

Germany

claudia.maienborn@uni-tuebingen.de
Johanna Herdtfelder

SFB 833

University of Tübingen

Nauklerstr. 35

72074 Tübingen

Germany

johanna.herdtfelder@uni-tuebingen.de 